\title{
CB1 cannabinoid receptor expression in the striatum: association with corticostriatal circuits and developmental regulation
}

\author{
Vincent Van Waes ${ }^{\dagger}$, Joel A. Beverley, Homayoun Siman, Kuei Y. Tseng and Heinz Steiner* \\ Department of Cellular and Molecular Pharmacology, The Chicago Medical School, Rosalind Franklin University of Medicine and Science, North Chicago, IL, USA
}

\section{Edited by:}

Joseph F. Cheer, University of

Maryland School of Medicine, USA

Reviewed by:

David M. Lovinger, National Institutes of Health, USA

Jason B. Wu, Cedars-Sinai Medical

Center, USA

Miles Herkenham, National Institutes

of Health, USA

\section{${ }^{*}$ Correspondence:}

Heinz Steiner, Department of Cellular and Molecular Pharmacology, The Chicago Medical School, Rosalind

Franklin University of Medicine and

Science, 3333 Green Bay Road, North

Chicago, IL 60064, USA.

e-mail: heinz.steiner@

rosalindfranklin.edu

\section{${ }^{\dagger}$ Present address:}

Vincent Van Waes, Laboratory of Integrative and Clinical

Neurosciences, University of Franche-Comté, 25000 Besançon, France
Corticostriatal circuits mediate various aspects of goal-directed behavior and are critically important for basal ganglia-related disorders. Activity in these circuits is regulated by the endocannabinoid system via stimulation of CB1 cannabinoid receptors. CB1 receptors are highly expressed in projection neurons and select interneurons of the striatum, but expression levels vary considerably between different striatal regions (functional domains). We investigated CB1 receptor expression within specific corticostriatal circuits by mapping CB1 mRNA levels in striatal sectors defined by their cortical inputs in rats. We also assessed changes in CB1 expression in the striatum during development. Our results show that CB1 expression is highest in juveniles (P25) and then progressively decreases toward adolescent (P40) and adult (P70) levels. At every age, CB1 receptors are predominantly expressed in sensorimotor striatal sectors, with considerably lower expression in associative and limbic sectors. Moreover, for most corticostriatal circuits there is an inverse relationship between cortical and striatal expression levels. Thus, striatal sectors with high CB1 expression (sensorimotor sectors) tend to receive inputs from cortical areas with low expression, while striatal sectors with low expression (associative/limbic sectors) receive inputs from cortical regions with higher expression (medial prefrontal cortex). In so far as CB1 mRNA levels reflect receptor function, our findings suggest differential CB1 signaling between different developmental stages and between sensorimotor and associative/limbic circuits. The regional distribution of $\mathrm{CB} 1$ receptor expression in the striatum further suggests that, in sensorimotor sectors, CB1 receptors mostly regulate GABA inputs from local axon collaterals of projection neurons, whereas in associative/limbic sectors, CB1 regulation of GABA inputs from interneurons and glutamate inputs may be more important.

\section{INTRODUCTION}

Anatomical circuits interconnecting the cerebral cortex and the basal ganglia are critical for the organization of goal-directed behavior, and dysfunction in these circuits is associated with numerous brain disorders, ranging from movement disorders to obsessive compulsive disorder, schizophrenia, and drug addiction, depending on the particular circuits affected (e.g., Albin et al., 1989; DeLong, 1990; Hyman and Nestler, 1996; Graybiel and Rauch, 2000; Steiner, 2010). Cortico-basal ganglia circuits arise from all parts of the cortex and project in a topographical manner to the striatum (caudate-putamen, nucleus accumbens), and from there, via basal ganglia output nuclei and thalamus, back to the cortex (Alexander et al., 1986, 1990; Albin et al., 1989; Groenewegen et al., 1990; Joel and Weiner, 1994). Activity within these circuits is modulated by a variety of G-protein-coupled receptors. Among these, the $\mathrm{G}_{\mathrm{i}}$-protein-coupled $\mathrm{CB} 1$ cannabinoid receptor is of highest abundance (Herkenham et al., 1990, 1991b). CB1 receptors are the main target for endocannabinoids (fatty acid signaling molecules) and mediate the pharmacological actions of cannabinoid drugs (for reviews, see Kreitzer and Regehr, 2002; Freund et al., 2003; Szabo and Schlicker, 2005; Lovinger et al., 2010). In the basal ganglia, CB1 receptors are predominantly expressed by striatal neurons, and are heavily localized on axon terminals within the striatum, as well as in target nuclei of striatal projection neurons, the substantia nigra and globus pallidus (Herkenham et al., 1991a,b; Mailleux and Vanderhaeghen, 1992; Matsuda et al., 1993). Lower levels of CB1 receptors are also present throughout the cortex (Herkenham et al., 1991b; Mailleux and Vanderhaeghen, 1992; Matsuda et al., 1993; Heng et al., 2011), including in corticostriatal neurons (Uchigashima et al., 2007).

Research over the last decade has shown that endocannabinoid/CB1 receptor signaling exerts powerful inhibitory effects on both glutamatergic and GABAergic synaptic transmission in the basal ganglia and many other brain regions. Typically, endocannabinoids are formed in activated neurons, released from the postsynaptic membrane, and diffuse to and stimulate CB1 receptors on presynaptic terminals to modulate transmitter release (Kreitzer and Regehr, 2002; Freund et al., 2003; Szabo and Schlicker, 2005; Lovinger et al., 2010). Considering the prominence of CB1 receptors in cortico-basal ganglia circuits, it is not surprising that 
cannabinoids have been implicated in pathophysiology and/or treatment of many of the disorders associated with these circuits, including Parkinson's and Huntington's disease, levodopa-induced dyskinesia, psychostimulant addiction, and schizophrenia (e.g., Romero et al., 2002; Brotchie, 2003; van der Stelt and Di Marzo, 2003; Wiskerke et al., 2008; Koethe et al., 2009; McCallum and Cheer, 2009; Lovinger et al., 2010; Casadio et al., 2011). The precise roles of $\mathrm{CB} 1$ receptors in these disorders remain to be determined; however, they will depend on the particular corticostriatal circuits involved.

The present study assessed the expression of $\mathrm{CB} 1$ receptors in the various corticostriatal circuits, by mapping $\mathrm{CB} 1 \mathrm{mRNA}$ throughout the striatum and associating this striatal expression with CB1 expression in cortical input regions (Heng et al., 2011). Our mapping approach used here was previously developed to assign drug-induced molecular changes in the striatum to specific corticostriatal circuits (Willuhn et al., 2003; Yano and Steiner, 2005). Studies indicate that some of the effects of cannabinoid drugs are especially critical during early brain development (see Heng et al., 2011). We thus measured and compared CB1 expression in these circuits at three different postnatal ages, in juveniles (postnatal day 25, P25), adolescents (P40), and adults (P70).

\section{MATERIALS AND METHODS SUBJECTS}

CB1 mRNA expression was studied in male Sprague-Dawley rats (Harlan, Madison, WI, USA) at P25, P40, and P70 ( $n=6$ each). All procedures met the NIH guidelines for the care and use of laboratory animals and were approved by the Rosalind Franklin University Animal Care and Use Committee.

\section{TISSUE PREPARATION AND IN SITU HYBRIDIZATION HISTOCHEMISTRY}

The rats were killed with $\mathrm{CO}_{2}$, and their brain was rapidly removed, frozen in isopentane cooled on dry ice and then stored at $-30^{\circ} \mathrm{C}$ until cryostat sectioning. Twelve micrometer thick coronal sections were thaw-mounted onto glass slides (Superfrost/Plus, Daigger, Wheeling, IL, USA) and dried on a slide warmer. In preparation for the in situ hybridization histochemistry, the sections were fixed in $4 \%$ paraformaldehyde $/ 0.9 \%$ saline for $10 \mathrm{~min}$ at room temperature, incubated in a fresh solution of $0.25 \%$ acetic anhydride in $0.1 \mathrm{M}$ triethanolamine/0.9\% saline ( $\mathrm{pH} 8.0$ ) for $10 \mathrm{~min}$, dehydrated, defatted for $2 \times 5 \mathrm{~min}$ in chloroform, rehydrated, and air-dried. The slides were then stored at $-30^{\circ} \mathrm{C}$ until hybridization.

The oligonucleotide probe (48-mer; Invitrogen, Rockville, MD, USA) was labeled with [35S]-dATP as described earlier (Willuhn et al., 2003). The probe was complementary to bases 1051-1098 of the CB1 mRNA (GenBank accession number X55812). One hundred microliter of hybridization buffer containing labeled probe $\left(\sim 3 \times 10^{6} \mathrm{cpm}\right)$ was added to each slide. The sections were coverslipped and incubated at $37^{\circ} \mathrm{C}$ overnight. After incubation, the slides were first rinsed in four washes of $1 \mathrm{X}$ saline citrate $(150 \mathrm{mM}$ sodium chloride, $15 \mathrm{mM}$ sodium citrate), and then washed 3 times $20 \mathrm{~min}$ each in $2 \mathrm{X}$ saline citrate $/ 50 \%$ formamide at $40^{\circ} \mathrm{C}$, followed by two washes of $30 \mathrm{~min}$ each in $1 \mathrm{X}$ saline citrate at room temperature. After a brief water rinse, the sections were air-dried and then apposed to X-ray film (BioMax MR-2, Kodak) for 3 days.

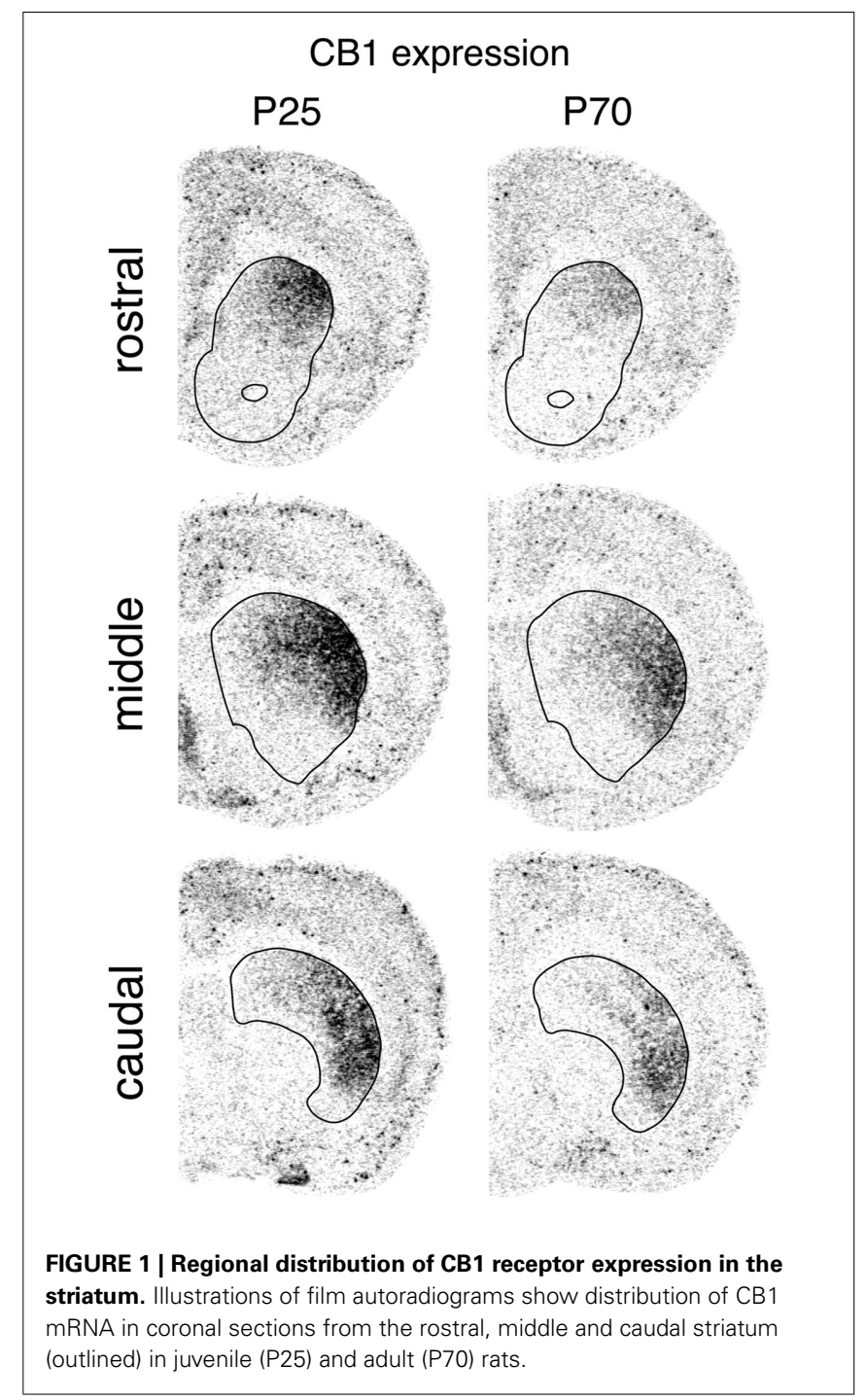

\section{ANALYSIS OF AUTORADIOGRAMS}

Gene expression was assessed in sections from 3 rostrocaudal levels (rostral, approximately at $+1.6 \mathrm{~mm}$ relative to bregma, Paxinos and Watson, 1998; middle, +0.4; and caudal, -0.8 ; Figure 1), in a total of 23 striatal sectors mostly defined by their predominant cortical inputs (Figure 2; Willuhn et al., 2003). Eighteen of these sectors represented the caudate-putamen and five the nucleus accumbens (Yano and Steiner, 2005). Hybridization signals on film autoradiograms were measured by densitometry $(\mathrm{NIH}$ Image; Wayne Rasband, NIMH, Bethesda, MD, USA). The film images were captured using a light table (Northern Light, Imaging Research, St. Catharines, ON, Canada) and a Sony CCD camera (Imaging Research). The "mean density" value of a region of interest was measured by placing a template over the captured image. Mean densities were corrected for background by subtracting mean density values measured over white matter (corpus callosum). Values from corresponding regions in the two hemispheres were then averaged.

Treatment effects were determined by one- or two-factor ANOVA, followed by Newman-Keuls post hoc tests to describe 


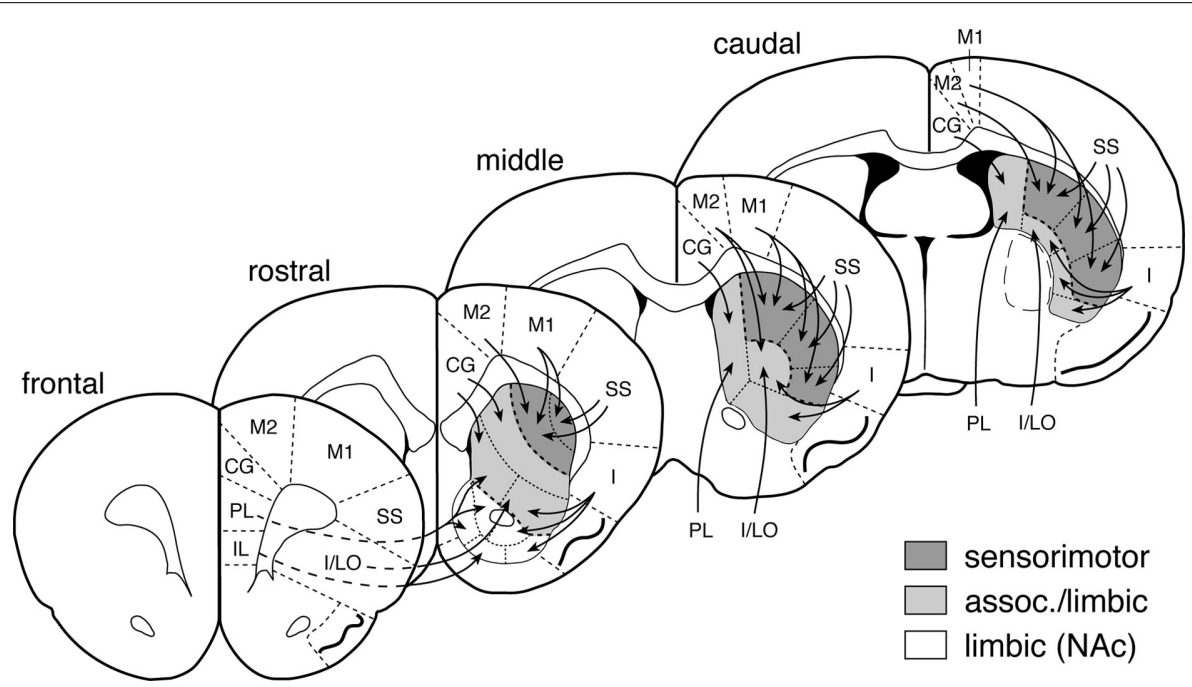

FIGURE 2 | Striatal sectors and their cortical inputs. Schematic illustration depicts the 23 striatal sectors in which CB1 expression was measured. The predominant cortical inputs to these sectors are indicated by arrows (simplified; see Willuhn et al., 2003). Sensorimotor, associative/limbic, and limbic/nucleus accumbens (NAc) circuits are indicated by shading Abbreviations (medial-lateral): IL, infralimbic; $\mathrm{PL}$, prelimbic; $\mathrm{CG}$, cingulate; M2, medial agranular; M1, motor; SS, somatosensory; I/LO, insular/lateral orbital; I, insular. differences between individual groups (Statistica, StatSoft, Tulsa, OK, USA). For illustrations of topographies (maps), gene expression in a given region was expressed relative to the maximal value (\% of max.) observed in the P25 group. The illustrations of film autoradiograms displayed in Figure $\mathbf{1}$ are computer-generated images, and are contrast-enhanced. Maximal hybridization signal is black.

\section{RESULTS \\ REGIONAL DISTRIBUTION OF CB1 RECEPTOR EXPRESSION IN THE STRIATUM}

$\mathrm{CB} 1$ receptor expression in the striatum displayed distinctive regional variations that were very similar in the three age groups (Figures 1, 3, and 4). CB1 mRNA levels were minimal ventrally and medially, and highest in the dorsolateral and ventrolateral sectors. Minimal CB1 mRNA expression was detected in the nucleus accumbens at any age (Figures 1, 3, and 4). These results show that the CB1 receptor is predominantly expressed in the sensorimotor sectors of the striatum, with minor to minimal expression in associative/limbic striatal regions.

\section{DEVELOPMENTAL TRAJECTORY OF CB1 mRNA EXPRESSION}

Despite the dramatic differences in expression levels between different striatal sectors, changes in CB1 expression across development were, overall, similar for all sectors. CB1 mRNA levels were maximal at P25 (Figure 1) and then decreased progressively to P40 and to P70 (Figures 3 and 4). Levels in adult animals were approximately $50-70 \%$ of those in juveniles. Statistical analysis revealed that, at P70, 16 of the 18 sectors of the caudate-putamen and one nucleus accumbens sector showed significantly lower levels, as compared to that at P25 ( $P<0.05$; Figures 3 and 4). From $\mathrm{P} 25$ to $\mathrm{P} 40$, a significant decrease was seen in 12 of the 18 caudateputamen sectors and 2 of the nucleus accumbens sectors (medial and lateral core; Figure 4), and from P40 to P70, in 11 of the caudate-putamen sectors and none of the nucleus accumbens sectors. Exceptions to this general developmental trajectory were found in the ventrolateral sectors on the middle and caudal levels. These sectors displayed either no statistically significant decrease (middle; Figures 3 and 4), or a significant but minor decrease (caudal; Figure 3) in CB1 expression across development, despite fairly high levels at P25.

\section{CB1 mRNA EXPRESSION IN SPECIFIC CORTICOSTRIATAL CIRCUITS}

To assess whether there was a relationship between cortical and striatal $\mathrm{CB} 1$ expression, we compared the marked regional variations in striatal CB1 mRNA levels shown here with variations in CB1 expression observed in the cortex (Heng et al., 2011). An overview indicated that striatal sectors with high levels of CB1 expression (e.g., sensorimotor sectors) received inputs mostly from cortical areas with relatively low CB1 levels (motor, somatosensory), whereas striatal sectors with low CB1 mRNA levels (associative/limbic) received afferents from cortical areas with higher CB1 expression (cingulate, insular). We thus assessed whether such an inverse relationship between cortical and striatal CB1 expression existed for specific corticostriatal circuits. We compared, for all 23 corticostriatal circuits, CB1 mRNA levels in cortical areas (Heng et al., 2011) with those in their striatal target sectors, according to the connectivity depicted in Figure 2. For striatal sectors with more than one cortical input region (Figure 2), the values of these cortical regions were averaged. Data from P25, P40, and P70 animals were initially averaged for this analysis.

Figure 5 shows the relationship between cortical and striatal CB1 mRNA levels for the 8 sensorimotor and 15 associative/limbic circuits (defined by their striatal target sectors, Figure 2; see Willuhn et al., 2003). For these 23 circuits pooled, there was only a tendency for a negative correlation between cortical and striatal CB1 expression $(r=-0.35, P=0.10)$. However, visual inspection 


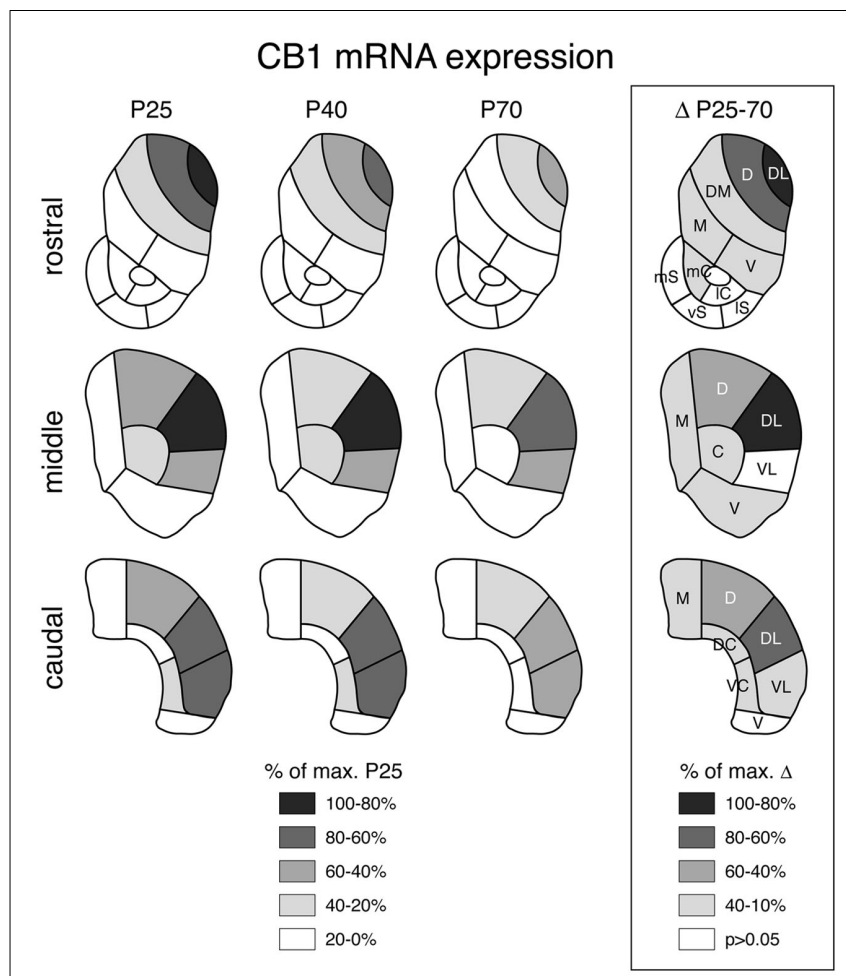

FIGURE 3 | Topography of striatal CB1 receptor expression at different postnatal ages and decreases in expression between juvenile and adult rats. Maps depict the distribution of CB1 mRNA in the rostral, middle, and caudal striatum in juveniles (P25), adolescents (P40) and adults (P70) (left) and the differences in expression between P25 and P70 animals (boxed; right). The data are normalized relative to the maximal value at P25 (left) or the maximal difference (right) (\% of max.), and the values and significant decreases $(P<0.05)$ are coded as indicated. Abbreviations: caudate-putamen: $\mathrm{C}$, central; D, dorsal; DC, dorsal central; DL, dorsolateral; DM, dorsomedial; $M$, medial; V, ventral; VC, ventral central; VL, ventrolateral; nucleus accumbens: $\mathrm{mC}$, medial core; IC, lateral core; $\mathrm{mS}$, medial shell; vS, ventral shell; IS, lateral shell.

revealed three different clusters in the value distribution, indicating that cohorts of circuits with different relationships existed (Figure 5A). Further post hoc analysis showed that the eight sensorimotor circuits by themselves displayed a more robust tendency for a negative correlation $(r=-0.67, P=0.07)$. In contrast, no such relationship was seen when the 15 associative/limbic circuits were considered as a group $(r=-0.16)$. However, the scatterplot (Figure 5A) shows that these latter circuits consisted of two clusters, seven circuits involving projections from medial prefrontal cortical areas (cingulate, prelimbic, infralimbic; Figure 2), which have relatively high levels of CB1 expression (Heng et al., 2011), and eight circuits with connections from lateral (insular) cortical areas, which show relatively low CB1 expression (Figure 5A). The seven medial prefrontal-striatal circuits indeed displayed the same inverse relationship between cortical and striatal CB1 expression as the sensorimotor circuits. Thus, when pooled ( $n=15$, Figure 5B), these circuits showed a very robust negative correlation for cortical and striatal CB1 expression $(r=-0.92, P<0.0001)$. This relationship was age-independent; it was also found when the different age groups were analyzed separately $(\mathrm{P} 25, r=-0.90, P<0.0001$;

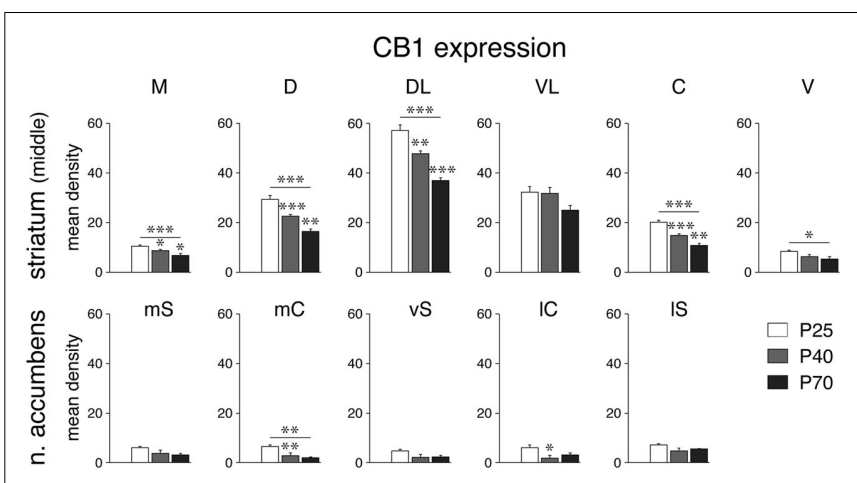

FIGURE 4 | Decrease in CB1 receptor expression during development in select striatal sectors. Mean density values (mean \pm SEM) for CB1 expression at P25, P40 and P70 are given for the six sectors of the middle striatum (top) and the five sectors of the nucleus accumbens (bottom) (for abbreviations, see Figure 3). ${ }^{*} P<0.05,{ }^{*} P<0.01$, ${ }^{*}{ }^{*} P<0.001$, vs. preceding age group or as indicated.

P40, $r=-0.91, P<0.0001$; P70, $r=-0.81, P<0.0001)$. These findings suggest that the regional expression of $\mathrm{CB} 1$ receptors is related between cortical areas and their functionally associated striatal sectors, an effect that is already present at P25 and remains unchanged through adolescence to adulthood.

\section{DISCUSSION}

The main findings of our present study include (1) detailed expression maps of $\mathrm{CB} 1$ receptors in the striatum with reference to functional domains/corticostriatal circuits; (2) a description of the developmental changes in striatal CB1 expression from juveniles to adolescents to adults; and (3) the relationship between $\mathrm{CB} 1$ expression in specific striatal sectors and CB1 expression in their cortical input regions.

\section{ASSOCIATION OF CB1 RECEPTOR EXPRESSION WITH FUNCTIONAL DOMAINS IN THE STRIATUM}

Our present study associated striatal CB1 expression with specific functional domains/corticostriatal circuits. The functional domains of the striatum are determined by inputs from the cortex (Joel and Weiner, 1994; Parent and Hazrati, 1995). We thus mapped the distribution of CB1 mRNA using 23 striatal sectors on 3 rostrocaudal levels that were previously designed to mostly reflect cortical inputs, based on anatomical tract tracing and functional imaging studies (see Willuhn et al., 2003; Yano and Steiner, 2005). Functional validation and limitations of this mapping approach have been discussed in detail elsewhere (Steiner, 2010). Given the topographical organization of corticostriatal projections, these sectors denote to some degree independent corticostriatal circuits; however, for descriptive purposes, these circuits are also grouped here into the broader categories of "sensorimotor" and "associative/limbic" (Joel and Weiner, 1994, 2000).

Our findings are overall consistent with previous work showing enriched localization of CB1 mRNA in the lateral striatum in rodents (Mailleux and Vanderhaeghen, 1992; Matsuda et al., 1993; Marsicano and Lutz, 1999; Steiner et al., 1999). Our study extends previous findings by providing more fine-grained distribution maps. For example, our results show that CB1 expression is largely 


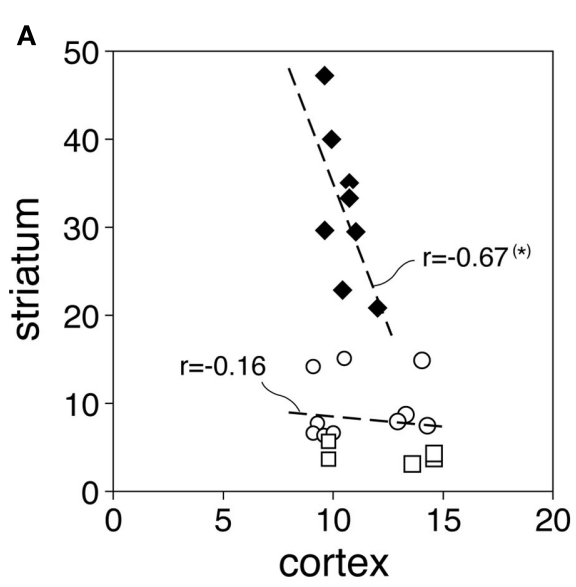

FIGURE 5 | Inverse relationship between cortical and striatal CB1 expression in specific corticostriatal circuits. The scatterplots $(\mathbf{A}, \mathbf{B})$ depict CB1 expression (mean density; P25, P40, P70 averaged) in cortical areas and their striatal target sectors for the 23 corticostriatal circuits examined. Values for the 8 sensorimotor circuits (diamonds), 10 associative/limbic circuits

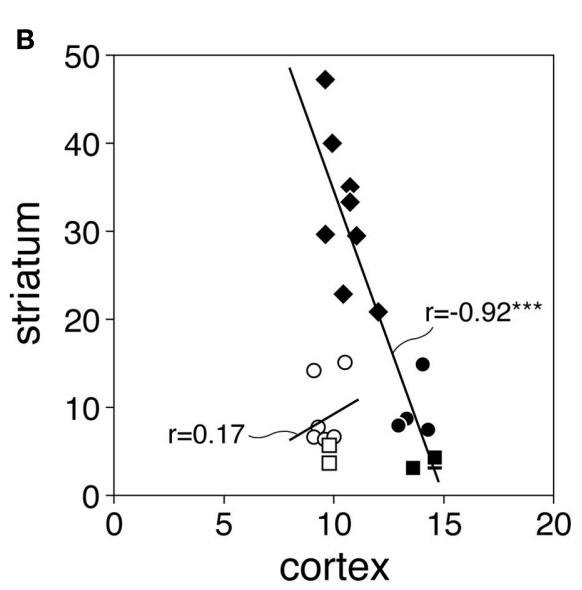

(circles), and 5 limbic/NAc circuits (squares) are displayed. Results (B) show a negative correlation between cortical and striatal CB1 expression for pooled sensorimotor circuits plus associative/limbic/NAc circuits with inputs from medial prefrontal cortex (IL, PL, CG; see Figure 2) (filled symbols, $n=15$; $\left.r=-0.92,{ }^{* *} P<0.0001\right)$. ${ }^{(*)} P=0.07$. restricted to the sensorimotor striatum, but expression differs between different sectors of the sensorimotor striatum. Thus, within the sensorimotor striatum, expression is highest in the dorsolateral and ventrolateral sectors that receive convergent inputs from the primary motor and somatosensory cortex (e.g., McGeorge and Faull, 1989; Brown et al., 1998; see Willuhn et al., 2003). $\mathrm{CB} 1$ expression is considerably lower in the dorsal sensorimotor sectors which differ in that they receive dense inputs also from the medial agranular (premotor) cortex, in addition to sensory and motor inputs (Reep et al., 1987, 2003). The functional significance of this differential expression is presently unclear, but we note that these same dorsal sectors show much more robust molecular adaptations after treatment with psychostimulants such as cocaine and methylphenidate than other parts of the sensorimotor striatum (Willuhn et al., 2003; Yano and Steiner, 2005; Steiner, 2010). Future studies will have to clarify the potential role of these striatal $\mathrm{CB} 1$ receptors in psychostimulant-induced neuroplasticity.

In contrast to the sensorimotor striatum, CB1 mRNA levels in associative/limbic sectors, including the nucleus accumbens, were found to be minimal to undetectable, in agreement with previous studies (Mailleux and Vanderhaeghen, 1992; Marsicano and Lutz, 1999; Steiner et al., 1999; Hohmann and Herkenham, 2000). These findings suggest that $\mathrm{CB} 1$ effects in these regions are likely mediated by $\mathrm{CB} 1$ receptors located on striatal afferents rather than on intrinsic neurons (see below).

In summary, to the extent that the here observed regional variations in CB1 mRNA levels are matched by CB1 receptor function, these findings indicate that $\mathrm{CB} 1$ receptors expressed by striatal neurons predominantly regulate sensorimotor processes of the striatum.

\section{DEVELOPMENTAL TRAJECTORY OF CB1 mRNA EXPRESSION IN CORTICOSTRIATAL CIRCUITS}

Our developmental analysis indicates that striatal CB1 expression is maximal in juvenile animals and then decreases toward adulthood. This effect was largely independent of the (greatly varying) expression levels observed in the different striatal sectors. This trajectory is similar to developmental changes found for other G-protein-coupled receptors. For example, early overexpression followed by pruning back to adult levels has also been shown for D1 and D2 dopamine receptors (Teicher et al., 1995; Andersen et al., 1997; Tarazi et al., 1999), A2 A adenosine receptors (Johansson et al., 1997), and the putative signaling molecule GPR88 (Van Waes et al., 2011).

A similar developmental decrease in CB1 expression from juveniles to adults was previously observed in cortical input regions of the various corticostriatal circuits (Heng et al., 2011). However, in that study, we noted a differential trajectory for changes in associative/limbic vs. sensorimotor cortical regions. Associative/limbic cortical regions showed a progressive reduction in CB1 expression from P25 to P40 to P70 (Heng et al., 2011), similar to most striatal sectors in the present study. In contrast, decreases in sensorimotor cortical regions mostly occurred only after the adolescent transition period (between P40 and P70; Heng et al., 2011), a developmental pattern of CB1 expression resembling that observed in the ventrolateral sensorimotor sectors of the middleto-caudal striatum. Collectively, these findings suggest that the maturation of CB1 expression within the associative/limbic corticostriatal circuits has an earlier onset than that in the sensorimotor domain, which occurs during adolescence.

\section{ARE CHANGES IN CB1 mRNA LEVELS REFLECTED BY CHANGES IN CB1 RECEPTOR FUNCTION?}

Previous findings showed that, in the striatum, the regional differences in $\mathrm{CB} 1$ receptor mRNA are matched by differences in $\mathrm{CB} 1$ receptor immunoreactivity and binding (Herkenham et al., 1991a,b; Mailleux and Vanderhaeghen, 1992; Egertová and Elphick, 2000; Julian et al., 2003). Are these molecular variations associated with corresponding differences in $\mathrm{CB} 1$ receptor function? 
Our previous study addressed the physiological significance of changes in CB1 mRNA levels by whole-cell patch clamp recordings (Heng et al., 2011). These experiments measured postsynaptic depolarization-induced suppression of excitation (DSE) in deeplayer pyramidal neurons of the medial prefrontal cortex during development (Heng et al., 2011). DSE is a well-established electrophysiological response used to determine endocannabinoid (CB1) regulation of synaptic activity (Kreitzer and Regehr, 2002; Lovinger et al., 2010). Our results demonstrated that DSE is indeed markedly reduced in the adult prefrontal cortex as compared with that in adolescent rats (Heng et al., 2011). These changes in DSE thus paralleled the changes in CB1 mRNA levels. DSE was associated with a facilitation of the paired-pulse ratio (Heng et al., 2011), indicating involvement of changes in presynaptic neurotransmitter release (Thomson, 2000). Moreover, DSE was inhibited by the $\mathrm{CB} 1$ receptor antagonist $\mathrm{AM}-251$, confirming that this effect was mediated by activation of CB1 receptors (Heng et al., 2011). Collectively, these electrophysiological findings indicate that this $\mathrm{CB} 1$ receptor function in the cortex is down-regulated during development, in parallel with the decrease in local CB1 receptor expression.

Nevertheless, the relationship between CB1 mRNA and function may be different in the striatum. It will be important to establish whether the differential CB1 mRNA levels, between different striatal regions and between developmental stages, are similarly accompanied by differential CB1 receptor function in striatal neurons.

\section{CELLULAR LOCALIZATION OF CB1 RECEPTORS IN THE STRIATUM: DIFFERENTIAL REGULATION OF GABA VS. GLUTAMATE SIGNALING IN DIFFERENT CORTICOSTRIATAL CIRCUITS?}

The distinctive differences in CB1 mRNA levels between striatal sectors in association with those in their cortical input regions allow for speculations regarding differential CB1 receptor signaling in the different corticostriatal circuits/functional domains.

The functional significance of these CB1 receptors is dependent on their cellular localization. Striatal CB1 binding reflects a combination of CB1 receptors located (1) on terminals of striatal afferents; (2) on striatal interneurons; and (3) on striatal projection neurons. We hypothesize that $\mathrm{CB} 1$ receptor binding in striatal sectors with high CB1 mRNA levels (and binding) mostly reflects receptors on striatal projection neurons, more precisely, on local axon collateral terminals of these projection neurons. This is supported by the following findings.

CB1 receptors on afferent terminals can not account for the distinct striatal binding patterns. For example, afferents from the cortex, although subject to significant presynaptic cannabinoid regulation (e.g., Lovinger et al., 2010, for review), express relatively low levels of CB1 receptors (e.g., Uchigashima et al., 2007; see also discussion in Freund et al., 2003). In fact, our results indicate an inverse relationship between cortical and striatal CB1 expression (i.e., striatal sectors with high $\mathrm{CB} 1 \mathrm{mRNA}$ levels and binding tend to receive inputs from cortical areas with low $\mathrm{CB} 1$ expression, and vice versa; Figure 5). Similarly, CB1 receptors on the other major afferents to the striatum, those from midbrain dopamine neurons and thalamic neurons, can hardly explain the observed patterns of striatal CB1 receptor binding, as these neurons show minimal or no CB1 mRNA/protein expression (Herkenham et al., 1991a; Mailleux and Vanderhaeghen, 1992; Julian et al., 2003; Uchigashima et al., 2007). CB1 receptors are expressed at greater levels in hippocampus and amygdala, although it remains unclear to what extent this expression is restricted to interneurons (Freund et al., 2003). However, inputs from these nuclei predominantly target the associative/limbic striatum (Joel and Weiner, 1994). They may thus contribute to CB1 binding in those sectors, but not in sensorimotor sectors.

Regarding the contribution of $\mathrm{CB} 1$ receptors on projection neurons vs. interneurons, colocalization studies demonstrate that CB1 receptors are very highly expressed in striatal projection neurons (Marsicano and Lutz, 1999; Hohmann and Herkenham, 2000; Martín et al., 2008). CB1 receptor expression is also established in (some) fast-spiking, parvalbumin-containing interneurons (Marsicano and Lutz, 1999; Hohmann and Herkenham, 2000; Martín et al., 2008) and may be present in a minority of NOS-containing and cholinergic interneurons (Fusco et al., 2004; Uchigashima et al., 2007). However, given that striatal interneurons in total only comprise a small fraction ( $3 \%$, Oorschot, 2010) of striatal neurons, the regional patterns of CB1 mRNA as depicted by film autoradiography (our studies) predominantly reflect expression in striatal projection neurons.

Where on projection neurons are these $\mathrm{CB} 1$ receptors localized? A prominent feature of striatal projection neurons is their extensive local axon collaterals that distribute roughly in a tissue volume similar to, and partly overlapping with, that of their dendrites (Gerfen and Bolam, 2010). These axon collaterals connect to interneurons and other projection neurons (Figure 6) and form numerous inhibitory (GABA) synapses onto spines and dendritic

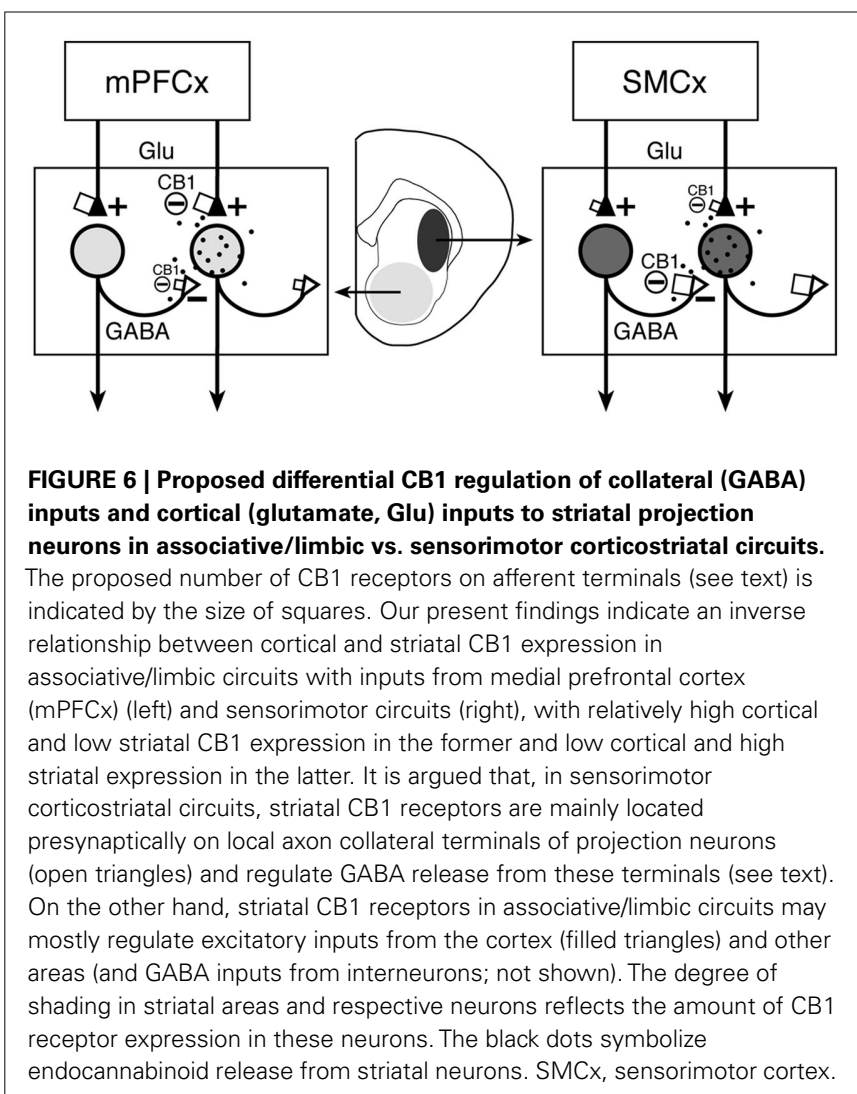


shafts of these neurons (Kubota and Kawaguchi, 2000; Wilson, 2007). Studies show that CB1 receptors are preferentially localized on axon terminals as opposed to postsynaptic elements ("polarized" distribution; Irving et al., 2000; McDonald et al., 2007). While some CB1 receptors have been found in dendritic profiles of striatal neurons (e.g., Rodriguez et al., 2001), this polarized distribution (Irving et al., 2000; McDonald et al., 2007) thus predicts much higher CB1 receptor levels on axon terminals of these neurons (Herkenham et al., 1991a). The importance of CB1 receptors on striatal axon collaterals has been demonstrated by electrophysiological findings. For example, stimulation of cannabinoid receptors inhibits GABAergic synaptic transmission between paired striatal projection neurons (Figure 6), and this effect is mediated by presynaptic $\mathrm{CB} 1$ receptors on axon terminals (Freiman et al., 2006).

Taken together, the above findings suggest that $\mathrm{CB} 1$ receptor binding in striatal sectors with high CB1 mRNA levels (sensorimotor sectors) largely reflects presynaptic $\mathrm{CB} 1$ receptors on local collateral terminals of projection neurons that regulate interactions between such neurons (Freiman et al., 2006; Figure 6). On the other hand, $\mathrm{CB} 1$ receptors in striatal areas with low CB1 mRNA levels (associative/limbic sectors, nucleus accumbens; e.g., Hoffman and Lupica, 2001; Manzoni and Bockaert, 2001) may mostly regulate GABA inputs from interneurons (e.g., Freiman et al., 2006), in addition to glutamate inputs from associative/limbic cortex and other brain regions.

\section{LIMITATIONS}

The above hypothesis will need to be tested experimentally. This hypothesis is based on measurement of mRNA, which is better

\section{REFERENCES}

Albin, R. L., Young, A. B., and Penney, J. B. (1989). The functional anatomy of basal ganglia disorders. Trends Neurosci. 12, 366-375.

Alexander, G. E., Crutcher, M. D., and DeLong, M. R. (1990). Basal gangliathalamocortical circuits: parallel substrates for motor, oculomotor, "prefrontal" and "limbic" functions. Prog. Brain Res. 85, 119-146.

Alexander, G. E., DeLong, M. R., and Strick, P. L. (1986). Parallel organization of functionally segregated circuits linking basal ganglia and cortex. Annu. Rev. Neurosci. 9, 357-381.

Andersen, S. L., Rutstein, M., Benzo, J. M., Hostetter, J. C., and Teicher, M. H. (1997). Sex differences in dopamine receptor overproduction and elimination. Neuroreport 8, 1495-1498.

Brotchie, J. M. (2003). CB1 cannabinoid receptor signalling in Parkinson's disease. Curr. Opin. Pharmacol. 3, 54-61.

Brown, L. L., Smith, D. M., and Goldbloom, L. M. (1998). Organizing principles of cortical integration in the rat neostriatum: corticostriate map of the body surface is an ordered lattice of curved laminae and radial points. J. Comp. Neurol. 392, 468-488.

Casadio, P., Fernandes, C., Murray, R. M., and Di Forti, M. (2011). risk for schizophrenia. Neurosci. Biobehav. Rev. 35, 1779-1787.

DeLong, M. R. (1990). Primate models of movement disorders of basal ganglia origin. Trends Neurosci. 13, 281-285.

Egertová, M., and Elphick, M. R. (2000). Localisation of cannabinoid receptors in the rat brain using antibodies to the intracellular C-terminal tail of CB1. J. Comp. Neurol. 422, 159-171.

Freiman, I., Anton, A., Monyer, H., Urbanski, M. J., and Szabo, B. (2006). Analysis of the effects of cannabinoids on identified synaptic connections in the caudateputamen by paired recordings in transgenic mice. J. Physiol. (Lond.) 575, 789-806.

Freund, T. F., Katona, I., and Piomelli, D. (2003). Role of endogenous cannabinoids in synaptic signaling. Physiol. Rev. 83, 1017-1066.

Fusco, F. R., Martorana, A., Giampà, C., De March, Z., Farini, D., D’Angelo, Cannabis use in young people: the

quantifiable than receptor immunohistochemistry and thus better suited for mapping studies. Moreover, mRNA "imaging" allows identification of the neurons (cell bodies) that express the receptor. In contrast, receptor binding signals can not differentiate between receptors on afferent terminals and those on postsynaptic neurons. Such a differentiation is necessary for the above considerations. However, the main caveat of the mRNA approach is that mRNA levels not always correlate with receptor levels and function. As stated above, while we have demonstrated parallel changes in CB1 mRNA levels and function for cortical neurons, a similar relationship in striatal neurons remains to be demonstrated.

\section{CONCLUSION: DIFFERENTIAL CB1 SIGNALING IN DIFFERENT CORTICOSTRIATAL CIRCUITS}

Our anatomical comparison of CB1 expression in cortex and striatum indicates an inverse relationship between cortical and striatal nodes of sensorimotor corticostriatal circuits and associative/limbic circuits receiving inputs from medial prefrontal cortex, with low cortical and high striatal expression and vice versa, respectively. These findings indicate that $\mathrm{CB} 1$ receptors differentially regulate corticostriatal transmission for these groups of circuits. Moreover, based on the above considerations, it can be hypothesized that, in sensorimotor corticostriatal circuits, exposure to cannabinoid drugs will predominantly affect striatal GABA release from local axon collaterals, whereas in associative/limbic circuits, cortical glutamate inputs are expected to be more affected.

\section{ACKNOWLEDGMENTS}

This work was supported in part by National Institutes of Health Grants DA011261 (Heinz Steiner) and MH086507 (Kuei Y. Tseng).

V., Sancesario, G., and Bernardi, G. (2004). Immunolocalization of CB1 receptor in rat striatal neurons: a confocal microscopy study. Synapse 53, 159-167.

Gerfen, C. R., and Bolam, J. P. (2010). "The neuroanatomical organization of the basal ganglia," in Handbook of Basal Ganglia Structure and Function, eds H. Steiner and K. Y. Tseng (London: Academic Press), 3-28.

Graybiel, A. M., and Rauch, S. L. (2000). Toward a neurobiology of obsessive-compulsive disorder. $\mathrm{Neu}$ ron $28,343-347$.

Groenewegen, H. J., Berendse, H. W. Wolters, J. G., and Lohman, A. H. (1990). The anatomical relationship of the prefrontal cortex with the striatopallidal system, the thalamus and the amygdala: evidence for a parallel organization. Prog. Brain Res. 85, 95-116.

Heng, L., Beverley, J. A., Steiner, H., and Tseng, K. Y. (2011). Differential developmental trajectories for CB1 cannabinoid receptor expression in limbic/associative and sensorimotor cortical areas. Synapse 65 , 278-286.
Herkenham, M., Lynn, A. B., de Costa B. R., and Richfield, E. K. (1991a). Neuronal localization of cannabinoid receptors in the basal ganglia of the rat. Brain Res. 547, 267-274.

Herkenham, M., Lynn, A. B., Johnson, M. R., Melvin, L. S., de Costa B. R., and Rice, K. C. (1991b). Characterization and localization of cannabinoid receptors in rat brain: a quantitative in vitro autoradiographic study. J. Neurosci. 11, 563-583.

Herkenham, M., Lynn, A. B., Little, M. D., Johnson, M. R., Melvin, L. S., de Costa, B. R., and Rice, K. C. (1990). Cannabinoid receptor localization in brain. Proc. Natl. Acad. Sci. U.S.A. 87, 1932-1936.

Hoffman, A. F., and Lupica, C. R. (2001). Direct actions of cannabinoids on synaptic transmission in the nucleus accumbens: a comparison with opioids. J. Neurophysiol. 85, 72-83.

Hohmann, A. G., and Herkenham, M. (2000). Localization of cannabinoid $\mathrm{CB}(1)$ receptor mRNA in neuronal subpopulations of rat striatum: a double-label in situ hybridization study. Synapse 37, 71-80. 
Hyman, S. E., and Nestler, E. J. (1996). Initiation and adaptation: a paradigm for understanding psychotropic drug action. Am. J. Psychiatry $153,151-162$.

Irving, A. J., Coutts, A. A., Harvey, J., Rae, M. G., Mackie, K., Bewick, G. S., and Pertwee, R. G. (2000). Functional expression of cell surface cannabinoid $\mathrm{CB}(1)$ receptors on presynaptic inhibitory terminals in cultured rat hippocampal neurons. Neuroscience 98, 253-262.

Joel, D., and Weiner, I. (1994). The organization of the basal gangliathalamocortical circuits: open interconnected rather than closed segregated. Neuroscience 63, 363-379.

Joel, D., and Weiner, I. (2000). The connections of the dopaminergic system with the striatum in rats and primates: an analysis with respect to the functional and compartmental organization of the striatum. Neuroscience 96, 451-474.

Johansson, B., Georgiev, V., and Fredholm, B. B. (1997). Distribution and postnatal ontogeny of adenosine $\mathrm{A} 2 \mathrm{~A}$ receptors in rat brain: comparison with dopamine receptors. Neuroscience 80, 1187-1207.

Julian, M. D., Martin, A. B., Cuellar, B., Rodriguez De Fonseca, F., Navarro, M., Moratalla, R., and Garcia-Segura, L. M. (2003). Neuroanatomical relationship between type 1 cannabinoid receptors and dopaminergic systems in the rat basal ganglia. Neuroscience 119, 309-318.

Koethe, D., Hoyer, C., and Leweke, F. M. (2009). The endocannabinoid system as a target for modelling psychosis. Psychopharmacology (Berl.) 206, 551-561.

Kreitzer, A. C., and Regehr, W. G. (2002). Retrograde signaling by endocannabinoids. Curr. Opin. Neurobiol. 12, 324-330.

Kubota, Y., and Kawaguchi, Y. (2000). Dependence of GABAergic synaptic areas on the interneuron type and target size. J. Neurosci. 20, 375-386.

Lovinger, D. M., Davis, M. I., and Costa, R. M. (2010). "Endocannabinoid signaling in the striatum," in Handbook of Basal Ganglia Structure and Function, eds H. Steiner and K. Y. Tseng (London: Academic Press), 167-186.

Mailleux, P., and Vanderhaeghen, J. J. (1992). Distribution of neuronal cannabinoid receptor in the adult rat brain: a comparative receptor binding radioautography and in situ hybridization histochemistry. Neuroscience 48, 655-668.

Manzoni, O. J., and Bockaert, J. (2001). Cannabinoids inhibit GABAergic synaptic transmission in mice nucleus accumbens. Eur. J. Pharmacol. 412, R3-R5.

Marsicano, G., and Lutz, B. (1999). Expression of the cannabinoid receptor $\mathrm{CB} 1$ in distinct neuronal subpopulations in the adult mouse forebrain. Eur. J. Neurosci. 11, 4213-4225.

Martín, A. B., Fernandez-Espejo, E., Ferrer, B., Gorriti, M. A., Bilbao, A., Navarro, M., Rodriguez de Fonseca, F., and Moratalla, R. (2008). Expression and function of CB1 receptor in the rat striatum: localization and effects on D1 and D2 dopamine receptor-mediated motor behaviors. Neuropsychopharmacology 33, 1667-1679.

Matsuda, L. A., Bonner, T. I., and Lolait, S. J. (1993). Localization of cannabinoid receptor mRNA in rat brain. $J$. Comp. Neurol. 327, 535-550.

McCallum, S. E., and Cheer, J. F. (2009). "Dopamine-endocannabinoid interactions in Parkinson's disease," in Cortico-Subcortical Dynamics in Parkinson's Disease, ed. K. Y. Tseng (Berlin: Springer), 185-205.

McDonald, N. A., Henstridge, C. M., Connolly, C. N., and Irving, A. J. (2007). An essential role for constitutive endocytosis, but not activity, in the axonal targeting of the CB1 cannabinoid receptor. Mol. Pharmacol. 71, 976-984.

McGeorge, A. J., and Faull, R. L. M. (1989). The organization of the projection from the cerebral cortex to the striatum in the rat. Neuroscience $29,503-537$.

Oorschot, D. E. (2010). "Cell types in the different nuclei of the basal ganglia," in Handbook of Basal Ganglia Structure and Function, eds H. Steiner and K. Y. Tseng (London: Academic Press), 63-74.

Parent, A., and Hazrati, L. N. (1995). Functional anatomy of the basal ganglia. I. The cortico-basal gangliathalamo-cortical loop. Brain Res Rev. 20, 91-127.

Paxinos, G., and Watson, C. (1998). The Rat Brain in Stereotaxic Coordinates. New York: Academic Press.

Reep, R. L., Cheatwood, J. L., and Corwin, J. V. (2003). The associative striatum: organization of cortical projections to the dorsocentral striatum in rats. J. Comp. Neurol. 467, 271-292.
Reep, R. L., Corwin, J. V., Hashimoto, A., and Watson, R. T. (1987). Efferent connections of the rostral portion of medial agranular cortex in rats. Brain Res. Bull. 19, 203-221.

Rodriguez, J. J., Mackie, K., and Pickel, V. M. (2001). Ultrastructural localization of the CB1 cannabinoid receptor in mu-opioid receptor patches of the rat caudate putamen nucleus. $J$. Neurosci. 21, 823-833.

Romero, J., Lastres-Becker, I., de Miguel, R., Berrendero, F., Ramos, J. A., and Fernández-Ruiz, J. (2002). The endogenous cannabinoid system and the basal ganglia. Biochemical, pharmacological, and therapeutic aspects. Pharmacol. Ther. 95, 137-152.

Steiner, H. (2010). "Psychostimulantinduced gene regulation in corticostriatal circuits," in Handbook of Basal Ganglia Structure and Function, eds H. Steiner and K. Y. Tseng (London: Academic Press), 501-525.

Steiner, H., Bonner, T. I., Zimmer, A. M., Kitai, S. T., and Zimmer, A. (1999). Altered gene expression in striatal projection neurons in CB1 cannabinoid receptor knockout mice. Proc. Natl. Acad. Sci. U.S.A. 96, 5786-5790.

Szabo, B., and Schlicker, E. (2005). Effects of cannabinoids on neurotransmission. Handb. Exp. Pharmacol. 168, 327-365.

Tarazi, F. I., Tomasini, E. C., and Baldessarini, R. J. (1999). Postnatal development of dopamine D1-like receptors in rat cortical and striatolimbic brain regions: an autoradiographic study. Dev. Neurosci. 21, 43-49.

Teicher, M. H., Andersen, S. L., and Hostetter, J. C. J. (1995). Evidence for dopamine receptor pruning between adolescence and adulthood in striatum but not nucleus accumbens. Brain Res. Dev. Brain Res. 89, 167-172.

Thomson, A. M. (2000). Facilitation, augmentation and potentiation at central synapses. Trends Neurosci. 23, 305-312.

Uchigashima, M., Narushima, M. Fukaya, M., Katona, I., Kano, M., and Watanabe, M. (2007). Subcellular arrangement of molecules for 2arachidonoyl-glycerol-mediated retrograde signaling and its physiological contribution to synaptic modulation in the striatum. J. Neurosci. 27 3663-3676. van der Stelt, M., and Di Marzo, V. (2003). The endocannabinoid system in the basal ganglia and in the mesolimbic reward system: implications for neurological and psychiatric disorders. Eur. J. Pharmacol. 480, 133-150.

Van Waes, V., Tseng, K. Y., and Steiner, H. (2011). GPR88 - a putative signaling molecule predominantly expressed in the striatum: cellular localization and developmental regulation. Basal Ganglia 1, 83-89.

Willuhn, I., Sun, W., and Steiner, H. (2003). Topography of cocaineinduced gene regulation in the rat striatum: relationship to cortical inputs and role of behavioural context. Eur. J. Neurosci. 17, 1053-1066

Wilson, C. J. (2007). GABAergic inhibition in the neostriatum. Prog. Brain Res. 160, 91-110.

Wiskerke, J., Pattij, T., Schoffelmeer, A. N., and De Vries, T. J. (2008). The role of $\mathrm{CB} 1$ receptors in psychostimulant addiction. Addict. Biol. 13, 225-238.

Yano, M., and Steiner, H. (2005). Topography of methylphenidate (Ritalin)induced gene regulation in the striatum: differential effects on cfos, substance $\mathrm{P}$ and opioid peptides. Neuropsychopharmacology 30, 901-915.

Conflict of Interest Statement: The authors declare that the research was conducted in the absence of any commercial or financial relationships that could be construed as a potential conflict of interest.

Received: 12 October 2011; accepted: 07 February 2012; published online: 12 March 2012

Citation: Van Waes V, Beverley JA, Siman $H$, Tseng KY and Steiner $H$ (2012) CB1 cannabinoid receptor expression in the striatum: association with corticostriatal circuits and developmental regulation. Front. Pharmacol. 3:21. doi: 10.3389/fphar.2012.00021

This article was submitted to Frontiers in Neuropharmacology, a specialty of Frontiers in Pharmacology.

Copyright (c) 2012 Van Waes, Beverley, Siman, Tseng and Steiner. This is an open-access article distributed under the terms of the Creative Commons Attribution Non Commercial License, which permits non-commercial use, distribution, and reproduction in other forums, provided the original authors and source are credited. 